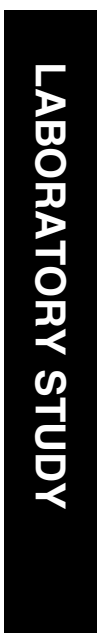

\section{Mesenchymal stem cell transplantation in a rabbit corneal alkali burn model: engraftment and involvement in wound healing}

${ }^{1}$ Eye Center, 2nd Affiliated Hospital of Zhejiang University, College of Medicine, Hangzhou, Zhejiang, China

2Department of Ophthalmology, Chung-Ang University Yongsan Hospital, Seoul, Korea

Correspondence: J Ye, Eye Center, 2nd Affiliated Hospital of Zhejiang University, College of Medicine, Hangzhou, Zhejiang, China Tel: + 8657187783897 ; Fax: + 8657187783897 . E-mail: YeJuan_99@ yahoo.com.cn

Received: 13 November 2004

Accepted in revised form: 17 March 2005:

Published online:

13 May 2005

The paper was presented in 2003 ARVO 891/B866.

Authors have no financial interest for this study. The work has not been published elsewhere and is not under review with another journal.

\begin{abstract}
Purpose To investigate whether systemically transplanted mesenchymal stem cells (MSCs) can home and engraft in tissue to promote cornea wound healing after alkali burn, as a new source for treatment.

Methods Corneal alkali burn was created in four group rabbits: Group I, normal bone marrow function, without MSCs transplantation; Group II, normal bone marrow function, with MSCs transplantation; Group III, bone marrow suppressed by cyclophosphamide, without MSCs; Group IV, bone marrow suppressed by cyclophosphamide, with MSCs. Clinical outcome was evaluated by cornea reepithelization, cornea opacity, and neovascularization. Cell engraftment into bone marrow, circulation, and cornea was monitored. Immunohistochemistry, using proliferating cell nuclear antigen (PCNA), P63, vimentin, and $\alpha$-smooth muscle actin ( $\alpha$-SMA) was carried out to assess the cell proliferative and differentiative ability.

Results At the time of 1-month follow-up, Group II rabbits showed the best clinical results with a clearer healed cornea compared with other groups. Well-formed neovascularization appeared on day 14 after alkali burn in Group II, that coincided with the maximum engraftment of MSCs. PCNA, P63, vimentin were more strongly expressed in Group II at multiple time points. DiI-labelled MSCs were differentiated into myofibroblast by the expression of $\alpha$-SMA. Delayed and insufficient cell engraftment, with malformed neovascularization and retarded corneal wound healing was found in Groups III and IV.
\end{abstract}

$\mathrm{J} \mathrm{Ye}^{1,2}, \mathrm{~K} \mathrm{YaO}^{1}$ and JC Kim²

Conclusions Systemically transplanted MSCs can engraft to injured cornea to promote wound healing, by differentiation, proliferation, and synergizing with haemotopoietic stem cells.

Eye (2006) 20, 482-490. doi:10.1038/sj.eye.6701913; published online 13 May 2005

Keywords: corneal wound healing; stem cell; transplantation

Introduction

Corneal alkali burn often causes extensive damage and results in permanent visual impairment. Recurrent epithelial erosions, corneal ulceration, severe stromal inflammation, and neovascularization are common clinical consequences of alkali burn. The destruction of limbal stem cells caused by this pathologic condition may account for the complications. ${ }^{1,2}$ Treatment of this severe disorder of the ocular surface remains a challenge. Although reports of the transplantation of corneal epithelial stem cells are promising, ${ }^{3,4}$ the feasibility and the long-term efficacy have been questioned.

The complex cellular arrangement found in the bone marrow stroma includes a subset of nonhaematopoietic cells referred to as mesenchymal stem cells (MSCs). These cells are multipotential and serve as long-lasting precursors for bone marrow, bone, cartilage, and connective tissue..$^{5-7}$ MSCs are being investigated for use in cell-based tissue engineering to repair or replace damaged tissue. ${ }^{8}$ An attractive feature of MSCs is their ability to be isolated from bone marrow, expanded in vitro, and utilized for 
transplantation. It remains unclear whether systemically administered MSCs can home and engraft in tissues in a clinically useful manner. The increasing recognition of the properties of MSCs has spawned a major change in our perception of the treatment of severe ocular surface disease. We hypothesized that induction of stress, such as corneal alkali burn, results in release of cytokines that recruit exogenously administered MSCs and, at the same time, increase bone marrow stem cell mobility, thereby facilitating mobilization of the MSCs into the circulation and to sites of wound healing. In the bone marrow microenvironment, MSCs proliferate, differentiate, support, and interact with haematopoietic stem cells (HSCs) to promote corneal wound healing after alkali burn. We used a bone marrow-suppressed model in which the host bone marrow stem cells were depleted and the function of transplanted MSCs could be tested.

The purpose of this study was to investigate whether systemically transplanted MSCs can be engrafted into wounded cornea and help promote corneal wound healing.

\section{Materials and methods}

\section{Isolation, expansion, and labelling of MSCs}

Bone marrow was harvested from the femurs of young rabbits $(0.5-1.0 \mathrm{~kg})$ after sedation with combined intramuscular administration of ketamine $(30 \mathrm{mg} / \mathrm{kg})$ and rompun $(5 \mathrm{mg} / \mathrm{kg})$. Isolation and expansion of MSCs were performed as previously described. ${ }^{9}$ Mononuclear cells were separated by centrifugation in a FicollHypaque gradient (density $1.077 \mathrm{~g} / \mathrm{cm}^{2}$; Sigma, St Louis, MO, USA), washed twice with Hanks' balanced saline solution (HBSS), and suspended in $\alpha$-minimum essential medium $(\alpha-\mathrm{MEM})$ containing $10 \%$ fetal calf serum (FCS; Gibco BRL, Grand Island, NY, USA). Cells were spread to a concentration of $1 \times 10^{6}$ cells $/ \mathrm{cm}^{2}$. Cultures were maintained at $37^{\circ} \mathrm{C}$ in a humidified atmosphere containing $5 \% \mathrm{CO}_{2}$. Haematopoietic cells and nonadherent cells were removed with changes in medium. Adherent cells after the second subculture, referred to as second generation MSCs, ${ }^{10}$ were used for the experiments. On the day of implantation, the MSCs were labelled with CM-DiI (Molecular Probes, Inc, Eugene, OR, USA), according to the manufacturer's protocol. Prior to intravenous injection, the cells were thoroughly washed and stored on ice at an approximate concentration of $1 \times 10^{7}$ cells $/ \mathrm{ml}$.

\section{Animal model}

A total of $60 \mathrm{New}$ Zealand White rabbits, each weighing between 2 and $2.5 \mathrm{~kg}$, were used in this experiment. ${ }^{11,12}$ Animal experiments were performed in a manner consistent with the ARVO Statement for the Use of Animals in Ophthalmic and Vision Research. Rabbits were randomly divided into four groups of 15 rabbits each. Group I, normal bone marrow function, corneal alkali burn without MSC transplantation; Group II, normal bone marrow function, cornea alkali burn with MSC transplantation; Group III, bone marrow suppressed by cyclophosphamide, corneal alkali burn without MSC transplantation; Group IV, bone marrow suppressed by cyclophosphamide, corneal alkali burn with MSC. Rabbits were anaesthetized with a combined intramuscular injection of ketamine and rompun. All the rabbits in Groups III and IV were intravenously injected with $100 \mathrm{mg} / \mathrm{kg}$ cyclophosphamide (ChoongWae Pharma Co., Korea) 2 days before the corneal burn was created. To create an alkali burn, a drop of $0.5 \%$ proparacaine was applied directly to one eye of the rabbit model; other eye served as control. Then, a $6 \mathrm{~mm}$ diameter Whatman Filter Paper soaked in $1 \mathrm{~N} \mathrm{NaOH}$ was applied to the cornea for $25 \mathrm{~s}$, including $4 / 5$ of upper peripheral cornea and $1 / 5$ of upper limbus, followed by a rinse with $10 \mathrm{ml}$ of balanced salt solution. After the corneal alkali burn was created, animals received neomycin-polymyxin B-dexamethasone eye drops (Maxitrol; Alcon-couvreur N.V, Belgium) four times daily for 2 weeks. At $24 \mathrm{~h}$ after the corneal alkali burn, all the Groups II and IV rabbits were anaesthetized as described above for MSC systemic administration. Prior to transplantation, the MSCs were DiI-labelled, washed twice, and resuspended in $1 \mathrm{ml}$ of $\alpha-\mathrm{MEM}$ at a concentration of $1 \times 10^{7}$ cells $/ \mathrm{ml}$. The injections were given through a ear vein with a 26 -gauge syringe. Five rabbits from each group were studied at different time points following alkali burn (days 3, 14, and 1 month). The animals were evaluated for clinical manifestations: corneal re-epithelization, corneal neovascularization, and opacification. After being killed, their samples (bone marrow, peripheral blood, and cornea) were collected to analyse the evidence of transplanted MSCs engraftment, proliferation, and differentiation.

\section{Follow-up and clinical outcome analysis}

After creation of the corneal alkali burn, each eye underwent slit-lamp examination, fluorescein staining, and photography at postoperative days 3,14 , and 1 month to document re-epithelization, opacification, and neovascularization of the cornea. The clinical outcome was evaluated by a masked investigator. The outcomes of five rabbits in each group at each set time point (days 3, 14, and 1 month) were used for statistical analysis: Kruskal-Wallis test and independent sample T-test (SPSS 10.0 for windows, SPSS Inc. Chicago, IL, USA). Criteria for the density of the opacity were: grade 0 , totally clear, 
with no opacity seen by any method of slit-lamp microscopic examination; grade 1 , haze of minimal density seen with difficulty with direct and diffuse illumination; grade 2 , mild haze easily visible with direct focal slit illumination; grade 3 , moderately dense opacity that partially obscured the iris details; and grade 4, severely dense opacity that completely obscured the details of intraocular structures. ${ }^{13}$ Corneal neovascularization was scored by the number and the length of newly developed vessels, as follows: ${ }^{14} 0$, no intracorneal vessels, normal corneoscleral limbus; 1 , less than five vascular loops, none longer than $0.3 \mathrm{~mm} ; 2,5-15$ vascular loops, none longer than $0.3 \mathrm{~mm}$; 3 , more than 15 vessels or loops longer than $0.3 \mathrm{~mm}$, and 4 , two or more loops longer than $0.5 \mathrm{~mm}$.

\section{Specimen preparation}

On each of the postoperative days 3, 14, and 1 month, five rabbits from Group II and IV were anaesthetized, and $2 \mathrm{ml}$ of peripheral blood was collected from a ear vein in a syringe containing $2000 \mathrm{U}$ of heparin. Rabbits were then killed by an air embolism. Bone marrow obtained from femurs was used to evaluate the engraftment of MSCs in bone marrow and the cellularity. Corneal blocks containing burned cornea and upper limbus in full thickness from four different groups were dissected at each time point.

\section{Monitoring MSC engraftment}

Mononuclear cells from bone marrow and peripheral blood were separated by centrifugation in a FicollHypaque and smeared on a slide. The slides were viewed and photographed under a fluorescein microscope (Olympus BH2-RFCA, Japan) equipped with a camera (Olympus C-35AD-4, Japan). The number of DiIprelabelled transplanted MSCs was counted in two different fields of each slide under $\times 400$ magnification. Fresh cornea tissues were flattened on slides and observed under a fluorescent microscope. Infiltrated MSCs were scored as follows: 0 , no infiltration; 1 , few scattered cells in selected area; 2 , scattered cells throughout field; 3 , dense infiltration.

\section{Immunohistochemical analysis}

Immunohistochemistry was carried out on paraffinembedded and optimal-cutting-temperature (OCT) compound-embedded corneal tissue, serial sectioning at $5 \mu \mathrm{m}$. For immunohistochemical analysis, paraffin sections were deparaffinized, rehydrated, dipped in 3\% hydrogen peroxide solution for $10 \mathrm{~min}$, and then processed with a labelled streptavidin-biotin kit
(Histostain-SP, Zymed, San Francisco, CA, USA). Antibodies examined included monoclonal mouse antivimentin, antiproliferating cell nuclear antigen (PCNA), and anti-P63 (Dako, Glostrup, Denmark). Peroxidase visualization was accomplished by adding a solution containing 3-amino-9-ethylcarbazole (AEC) and hydrogen peroxide. Finally, the sections were counterstained with haematoxylin. Immunofluorescence, using cryostat sections, was performed for the detection of $\alpha$-smooth muscle actin ( $\alpha$-SMA). FITC-conjugated mouse monoclonal anti- $\alpha$-SMA (Sigma, St Louis, MO, USA) was used. Corneal sections of the controlled eye of each rabbit served as control. The density of positive staining was graded as strong $(++)$, moderate $(+)$, or weak $( \pm)$, and only the strong and moderate stainings were considered to be positive. ${ }^{15}$

\section{Bone marrow function check}

Bone marrow collected from Groups I and III was checked for cellularity. Mononuclear cells from bone marrow were immunostained with primary polyclonal goat anti-CD34 and c-Kit antibodies (Santa Cruz Biotechnology, Santa Cruz, CA, USA), followed by FITCconjugated mouse anti-goat IgG secondary antibody (Sigma, St Louis, MO, USA). To evaluate the bone marrow suppressive effect of cyclophosphamide and the duration of suppression, stained positive cells were counted under a fluorescent microscope. To evaluate the bone marrow suppressive effect of cyclophosphamide and the duration of suppression, stained positive cells were counted under a fluorescent microscope.

\section{Results}

\section{Clinical results}

Clinical observation following alkali burn and MSC transplantation included evaluation of corneal opacity, neovascularization, epithelial defects, and reepithelization (Figure 1). Experimental rabbits developed recurrent corneal epithelial defects, and the time (days) required for re-epithelization after initial alkali injury in each group were as follows: Group I, 9.0 (range from 7.0 to 12.0); Group II, 6.9 (range from 6.0 to 10.0); Group III, 12.8 (range from 10.0 to 15.0); Group IV, 12.2 (range from 10.0 to 14.0 ). Neovascularization after injury varied among the four groups for the duration of the experiment. The majority of vessel ingrowth originated in a random fashion around the limbus toward the central cornea within the wounded area on postoperative day 3 in rabbits with normal bone marrow function and on postoperative days 7-10 in bone marrow-suppressed rabbits. The peak of neovascularization, with more loops 

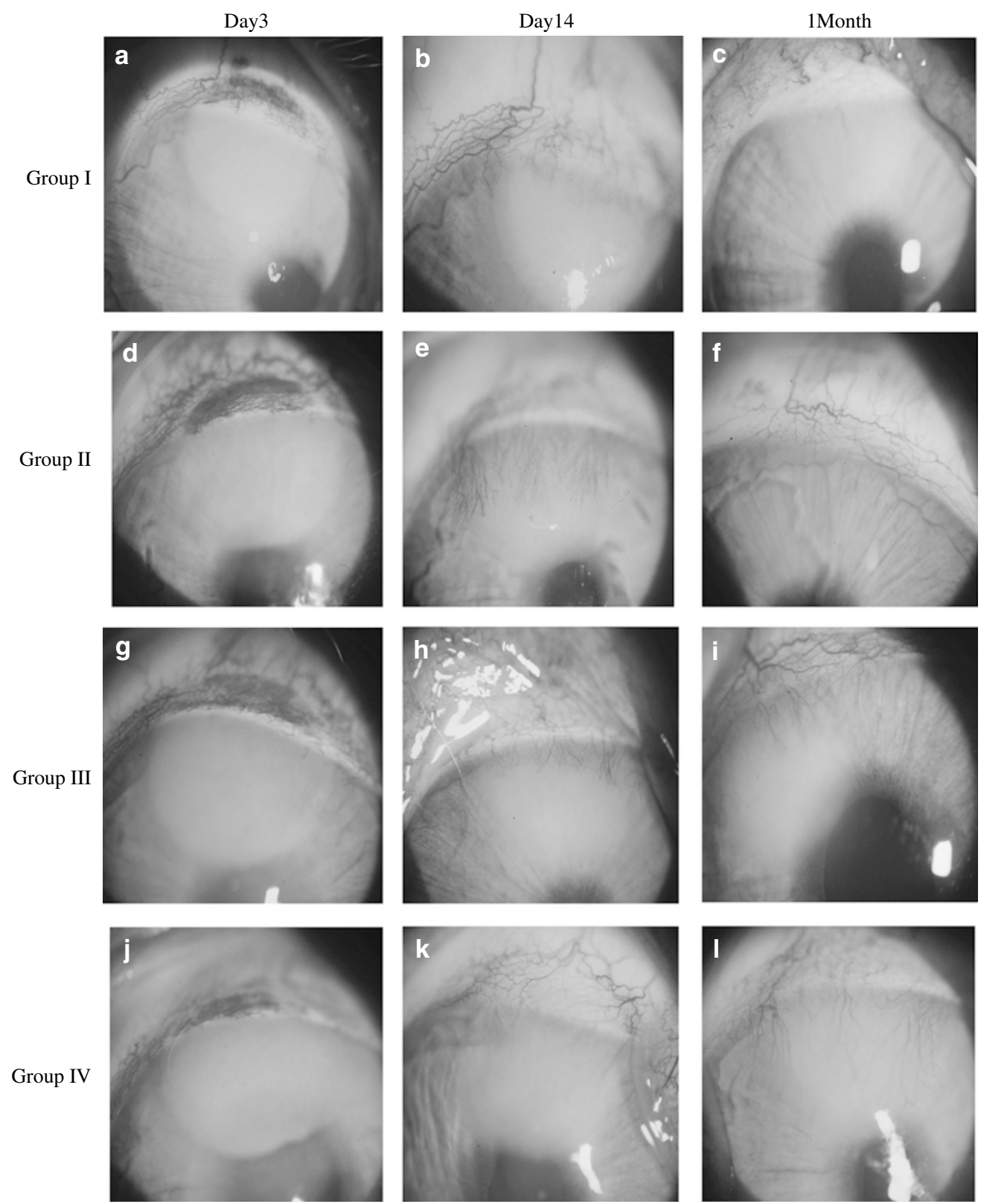

Figure 1 Examples of clinical outcome. Photography of day 3 after rabbit corneal alkali burn (a, d, g, j), day 14 (b, e, h, k), and at the time of 1-month follow-up (c, f, i, l).

and well-formed vessels, appeared early $\left(\chi^{2}=10.70\right.$, $P=0.013)$ and disappeared early $\left(\chi^{2}=7.64, P=0.050\right)$ in Group II, leaving a clearer cornea $\left(\chi^{2}=11.22, P=0.011\right)$ at the end of the 1-month follow-up. Compared with Group II, Group I rabbits had less new vessel $\left(\chi^{2}=5.77\right.$, $P=0.016$ ) development during the course of wound healing. Delayed corneal neovascularization with brushlike malformed new vessels was seen in bone marrowsuppressed rabbits in Groups III and IV. At 1 month, the corneal opacity and neovascularization were more severe in Groups III and IV. The opacities were still $5-6 \mathrm{~mm}$ in diameter, had a ground-glass appearance, and showed feathered edges that were distinct from the normal MSCtransplanted rabbits. There was no substantial difference of cornea opacity $\left(\chi^{2}=0.267, P=0.606\right)$ and neovascularization $\left(\chi^{2}=0.206, P=0.650\right)$ between Groups III and IV, but the outcome was relatively better in MSC-injected Group IV (Figure 2).

\section{MSCs engraftment}

Successful engraftment of MSCs occurred in all treated animals, as shown by the number of DiI-labelled cells seen on the microscope. Implanted MSCs could be 

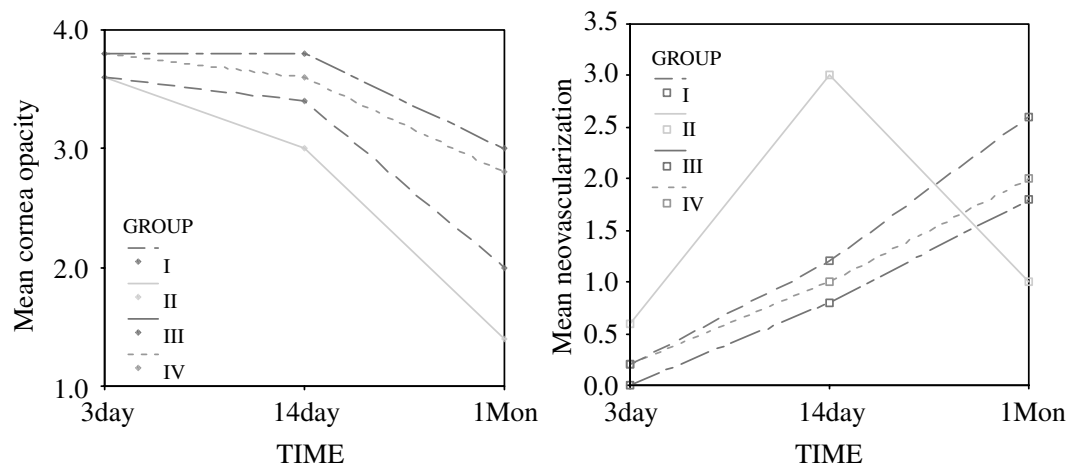

Figure 2 On day 3, 14, and 1 month comparison of cornea opacity and cornea neovascularization among four groups.

Table 1 Engrafted MSC in peripheral blood (PB) and bone marrow (BM) (mean \pm SD)

\begin{tabular}{|c|c|c|c|c|c|c|}
\hline & \multicolumn{2}{|c|}{ Day 3} & \multicolumn{2}{|c|}{ Day 14} & \multicolumn{2}{|c|}{1 month } \\
\hline & $P B$ & $B M$ & $P B$ & $B M$ & $P B$ & $B M$ \\
\hline Group II & $29.60 \pm 11.10$ & $51.00 \pm 14.14$ & $5.00 \pm 2.55$ & $6.80 \pm 3.42$ & $6.00 \pm 2.92$ & $5.60 \pm 3.21$ \\
\hline Group IV & $\begin{array}{c}38.80 \pm 10.57 \\
t=-1.342 \\
P=0.216\end{array}$ & $\begin{array}{c}47.00 \pm 13.93 \\
t=0.451 \\
P=0.664\end{array}$ & $\begin{array}{c}9.80 \pm 3.19 \\
t=-2.626 \\
P=0.030\end{array}$ & $\begin{array}{c}19.80 \pm 4.97 \\
t=-4.818 \\
P=0.001\end{array}$ & $\begin{array}{c}14.00 \pm 4.74 \\
t=-3.213 \\
P=0.012\end{array}$ & $\begin{array}{c}16.80 \pm 6.06 \\
t=-3.204 \\
P=0.013\end{array}$ \\
\hline
\end{tabular}

identified at the site of peripheral blood, bone marrow, wounded cornea, and limbus. The number of engrafted MSCs in peripheral blood and bone marrow at multiple time points in bone marrow-suppressed and normal rabbits is illustrated in Table 1. In Group II, transplanted MSCs rapidly engrafted to bone marrow on day 3 (2 days after injection). The MSCs in bone marrow then apparently decreased, while there was dense infiltration in the upper limbal area and a few scattered cells in the area of the corneal wound on day 3. Dense infiltration to corneal epithelium, stroma, and endothelium was observed on day 14 and scattered infiltration was observed at 1 month (Figure 3). In Group IV, transplanted MSCs slowly engrafted to bone marrow and remained there for a longer time before mobilization to the circulation, compared with Group II. Dense infiltration of MSCs in cornea was present at 1 month, whereas only scattered infiltration was present on days 3 and 14. Cells appeared to preferentially engraft in regions of alkaliburned cornea and assemble predominantly in the stroma.

\section{Immunohistochemistry}

To assess the proliferation and differentiation of corneal cells after MSC transplantation, immunohistochemistry was performed by using antibodies: P63, PCNA, vimentin, and $\alpha$-SMA. In addition to the impressive number of MSCs in the wounded cornea, colocalization of immunofluorescence indicates that a significant portion of the surviving engrafted cells had begun to express smooth muscle-specific $\alpha$-actin. Muscle-specific protein expression was observed as early as 14 days after transplantation in Group II and persisted at subsequent examination time points.

Compared to rabbits that did not receive MSC transplantation, the MSC-implanted rabbits showed strong expression of the limbal stem cell marker-P63 in the limbal and peripheral corneal epithelium basal layer on days 3 and 14, followed by a low level of expression at 1 month. Cell proliferative activity was demonstrated by PCNA. PCNA was expressed not only in the limbal basal layer, but it also extended from the periphery of the corneal epithelium to the central regenerated corneal epithelium in Group II. PCNA expression was much more pronounced on day 14, and it maintained a high level of expression at 1 month. The MSC-transplanted rabbits possessed high levels of vimentin in the stroma on day 14 and at 1 month, whereas the corneal stroma of rabbits without MSC transplantation demonstrated a very low level of vimentin expression (Figure 4).

\section{Bone marrow suppression}

Bone marrow biopsy showed that after application of cyclophosphamide, bone marrow cellularity dropped 

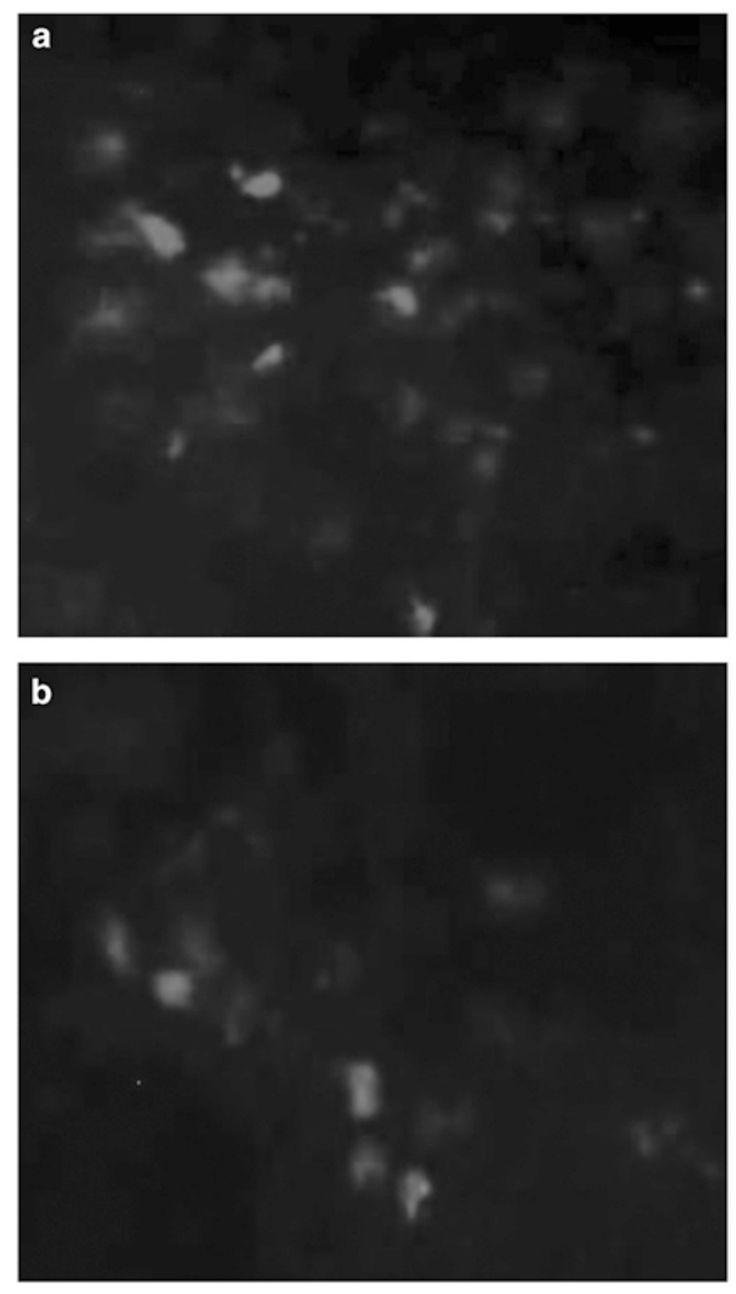

Figure 3 MSC infiltration in wounded cornea. Fresh-mounted wounded cornea from Group II (a) and Group IV (b) observed under fluorescein microscope. DiI-labelled MSCs engraft to cornea with red fluorescein on day 14 .

from 70 to $30-40 \%$. Fluorescein immunohistochemistry using HSC and MSC marker CD34 and c-Kit further confirmed the suppression effect by depleting stem cells to $5-10 \%$ of the original number. Bone marrow function had not recovered at the end of the 1-month follow up.

\section{Discussion}

To our knowledge, this is the first study illustrating that systemically transplanted MSCs significantly engraft to locally injured cornea. These multipotential stem cells can home to specific tissues, differentiate in response to the local microenvironment, and stimulate a local repair response, promoting corneal wound healing after alkali burn.
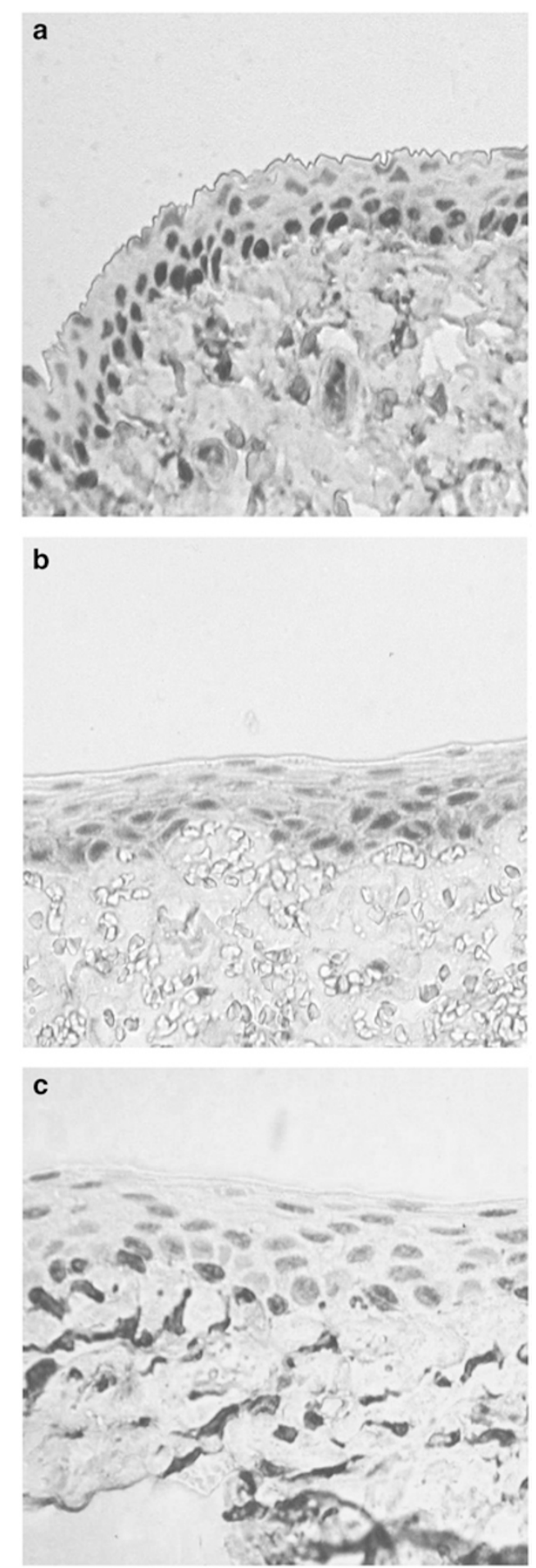

Figure 4 Immunohistochemistry of limbal and pheripheral cornea on day 14 after alkali burn in Group II. Pronounced expression of P63 (a) and PCNA (b) in basal epithelial layer. Vimentin was strongly expressed by stroma cells (c).

The bone marrow remains the primary site where stem cells undergo self-renewal and differentiation. ${ }^{16}$ We also 
noted that exogenously applied MSCs must home to the host bone marrow for self-renewal, full activation, and maturation before re-entering the circulation. Poor engraftment and delayed wound healing in the bone marrow-suppressed animal model, in spite of adequate numbers of functional transplanted stem cells, demonstrated the importance of an appropriate bone marrow environment to allow implanted stem cells to function actively and effectively. Our data suggest the critical cooperative work of MSCs and bone marrow haematopoietic progenitor and stem cells.

Neovascularization is essential for repair, remodelling, and regeneration of damaged tissue during corneal wound healing. ${ }^{1,17}$ Regarding the course of wound healing, we found that in rabbits with normal bone marrow function and MSC transplantation, more wellformed corneal vessels developed and disappeared earlier, leaving a clearer regenerated cornea. It is plausible that during steady-state conditions, HSCs reside in a quiescent state. ${ }^{18}$ Stress, such as alkali burn, results in the release of chemocytokines that increase stem cell motility, thereby facilitating their entry into the wound site microenvironment, where they proliferate, differentiate and contribute to neovascularization. ${ }^{19-21}$ Undifferentiated MSCs can respond to local cues in vivo to differentiate into endothelial cells, contributing to neovascularization in the setting of wound healing, ${ }^{22}$ but CD34-positive endothelial and hematopoietic progenitors and stem cells from bone marrow are most important during stress angiogenesis. ${ }^{21,23}$ Under bone marrow-suppressed conditions, decreased CD34-positive HSCs account for the delayed and malformed corneal neovascularization. Engrafted MSCs in the bone marrow microenvironment, which express various haematopoietic cytokines, including interleukin (IL)-6, IL-11, thrombopoietin (TPO), stem cell factor (SCF), and other molecules, could provide the appropriate milieu for efficient stimulation of quiescent HSCs. ${ }^{24-26}$ These activated HSCs released into the circulation, migrate to the wound site, thereby accelerating neovascularization.

MSCs are not restricted to producing specific cell types, namely those from the tissue in which they reside, emphasizing the enormous potential of these cells in both cell and gene therapy. ${ }^{16}$ The multilineage potential of human MSCs isolated from adult marrow and expanded to colonies was clearly demonstrated recently by Pittenger $\mathrm{et} \mathrm{al.}{ }^{27}$ These cultured cells display a spindleshape fibroblastic morphology. In the absence of differentiation stimuli and HSCs, MSCs maintain the properties of self-renewal and a capacity to regenerate mesenchymal tissues such as bone, cartilage, muscle, ligament, tendon, adipose, and stroma following extensive culture expansion. ${ }^{7,23}$ We used a more primitive population of MSC (second generation) in our study in order to demonstrate better engraftment and more widespread differentiation. ${ }^{28}$ MSCs engrafted to wounded cornea expressed $\alpha$-SMA, and at the same time point (day 14), pronounced expression of vimentin was detected in the regenerated corneal stroma. This is consistent with published data that the MSC population in general shares many properties of fibroblasts and, interestingly, expresses myofibroblastic cell markers $\alpha$ SMA and vimentin. ${ }^{10,29}$ Therefore, it is plausible that engrafted MSCs differentiate into myofibroblasts and stimulate existing fibroblasts to undergo myofibroblast transdifferentiation. The presence of myofibroblastic cells in wounded cornea is central to wound healing. ${ }^{30,31}$

We attempted to determine the kinetics of cell proliferation and limbal stem cell activity during wound healing of alkali burn by using stable cell cycle-regulated protein (PCNA) and corneal limbal stem cell-specific marker P63..$^{32}$ The presence of MSCs seems to stimulate the proliferation of limbal stem cells, as evidenced by PCNA expression. In our study, the expression of PCNA was clearly more extensive in basal epithelium and throughout the depth and surface of the epithelium on day 14 when the greatest number of MSCs was present in the corneas of Group II rabbits. This evidence is consistent with the clinical healing signs and indicates that the MSCs that migrated into the wounded limbal and corneal area exerted a positive influence on the native corneal cell proliferation. One possible explanation of increase in P63 expression on day 3 and its decrease on day 14, while PCNA was pronouncedly expressed on day 14 and thereafter, is that the engrafted MSCs in limbus may stimulate more limbal stem cells to express P63; these activated stem cells respond to the local special environment created by inflammatory reaction and release cytokines from MSCs, gaining the ability to proliferate and differentiate. This explanation is supported by the previous finding that P63 is expressed only by limbal stem cells that possess the ability to proliferate and not by cells that are undergoing terminal differentiation. ${ }^{33}$ We hypothesize that engrafted MSCs can promote wound healing by stimulating and synergizing with native cells.

Taken together, these observations strongly suggest that tissue injury-induced homing of systemically transplanted MSCs to particular sites with subsequent differentiation in response to local tissue microenvironment promotes wound healing. In normal bone marrow, MSCs support and enhance the response of HSCs to angiogenic stimuli and then HSCs can migrate to local sites, where they contribute to corneal neovascularization and promote wound healing.

Our findings represent a new and encouraging paradigm for treating cornea alkali burn and other ocular 
surface diseases by transplantation of multipotential MSCs either alone or in conjunction with HSCs. Further studies are needed to clarify the exact differentiative ability of local engrafted MSCs and the interaction of MSCs, HSCs, and native corneal cells.

\section{References}

1 Kao WW, Zhu G, Benza R, Kao CW, Ishizaki M, Wander AH. Appearance of immune cells and expression of MHC II DQ molecule by fibroblasts in alkali-burned corneas. Cornea 1996; 15(4): 397-408.

2 Tsubota K, Satake Y, Kaido M, Shinozaki N, Shimmura S, Bissen-Miyajima $\mathrm{H}$ et al. Treatment of severe ocular-surface disorders with corneal epithelial stem-cell transplantation. N Engl J Med 1999; 340(22): 1697-1703.

3 Holland EJ, Schwartz GS. The evolution of epithelial transplantation for severe ocular surface disease and a proposed classification system. Cornea 1996; 15: 549-556.

4 Swift GJ, Aggarwal RK, Davis GJ, Coster DJ, Williams KA. Survival of rabbit limbal stem cell allografts. Transplantation 1996; 62: 568-574.

5 Galmiche MC, Koteliansky VE, Briere J, Herve P, Charbord P. Stromal cells from human long-term marrow cultures are mesenchymal cells that differentiate following a vascular smooth muscle differentiation pathway. Blood 1993; 82(1): 66-76.

6 Pereira RF, Halford KW, O'Hara MD, Leeper DB, Sokolov $\mathrm{BP}$, Pollard MD et al. Cultured adherent cells from marrow can serve as long-lasting precursor cells for bone, cartilage, and lung in irradiated mice. Proc Natl Acad Sci USA 1995; 92(11): 4857-4861.

7 Prockop DJ. Marrow stromal cells as stem cells for nonhematopoietic tissues. Science 1997; 276(5309): 71-74.

8 Dennis JE, Carbillet JP, Caplan AI, Charbord P. The STRO$1+$ marrow cell population is multipotential. Cells Tissues Organs 2002; 170(2-3): 73-82.

9 Conget PA, Minguell JJ. Phenotypical and functional properties of human bone marrow mesenchymal progenitor cells. J Cell Physiol 1999; 181(1): 67-73.

10 Bianco P, Riminucci M, Gronthos S, Robey PG. Bone marrow stromal stem cells: nature, biology, and potential applications. Stem Cells 2001; 19(3): 180-192.

11 Ormerod LD, Abelson MB, Kenyon KR. Standard models of corneal injury using alkali-immersed filter discs. Invest Ophthalmol Vis Sci. 1989; 30(10): 2148-2153.

12 Kim JS, Kim JC, Na BK, Jeong JM, Song CY. Amniotic membrane patching promotes healing and inhibits proteinase activity on wound healing following acute corneal alkali burn. Exp Eye Res 2000; 70(3): 329-337.

13 Fantes FE, Hanna KD, Waring III GO, Pouliquen Y, Thompson KP, Savoldelli M. Wound healing after excimer laser keratomileusis (photorefractive keratectomy) in monkeys. Arch Ophthalmol 1990; 108(5): 665-675.

14 Deutsch TA, Hughes WF. Suppressive effects of indomethacin on thermally induced neovascularization of rabbit corneas. Am J Ophthalmol 1979; 87(4): 536-540.

15 Gan L, Fagerholm P, Kim HJ. Effect of leukocytes on corneal cellular proliferation and wound healing. Invest Ophthalmol Vis Sci 1999; 40(3): 575-581.
16 Kicic A, Shen W, Rakoczy PE. The potential of marrow stromal cells in stem cell therapy. Eye 2001; 15(Part 6): 695-707.

17 Folkman J. Angiogenesis in cancer, vascular, rheumatoid and other disease. Nat Med 1995; 1(1): 27-31.

18 Cheng T, Rodrigues N, Shen H, Yang Y, Dombkowski D, Sykes $\mathrm{M}$ et al. Hematopoietic stem cell quiescence maintained by p21cip1/waf1. Science 2000; 287(5459): 1804-1808.

19 Peled A, Petit I, Kollet O, Magid M, Ponomaryov T, Byk T et al. Dependence of human stem cell engraftment and repopulation of NOD/SCID mice on CXCR4. Science 1999; 283(5403): 845-848.

20 Heissig B, Hattori K, Dias S, Friedrich M, Ferris B, Hackett NR et al. Recruitment of stem and progenitor cells from the bone marrow niche requires MMP-9 mediated release of kitligand. Cell 2002; 109(5): 625-637.

21 Hattori K, Heissig B, Wu Y, Dias S, Tejada R, Ferris B et al. Placental growth factor reconstitutes hematopoiesis by recruiting VEGFR1 $(+)$ stem cells from bone-marrow microenvironment. Nat Med 2002; 8(8): 841-849.

22 Reyes M, Dudek A, Jahagirdar B, Koodie L, Marker PH, Verfaillie CM. Origin of endothelial progenitors in human postnatal bone marrow. J Clin Invest 2002; 109(3): 337-346.

23 Ferrara N, Alitalo K. Clinical applications of angiogenic growth factors and their inhibitors. Nat Med 1999; 5(12): 1359-1364.

24 Haynesworth SE, Baber MA, Caplan AI. Cytokine expression by human marrow-derived mesenchymal progenitor cells in vitro: effects of dexamethasone and IL-1 alpha. J Cell Physiol 1996; 166(3): 585-592.

25 Majumdar MK, Thiede MA, Mosca JD, Moorman M, Gerson SL. Phenotypic and functional comparison of cultures of marrow-derived mesenchymal stem cells (MSCs) and stromal cells. J Cell Physiol 1998; 176(1): $57-66$.

26 Mbalaviele G, Jaiswal N, Meng A, Cheng L, Van Den Bos C, Thiede M. Human mesenchymal stem cells promote human osteoclast differentiation from CD34 + bone marrow hematopoietic progenitors. Endocrinology 1999; 140(8): 3736-3743.

27 Pittenger MF, Mackay AM, Beck SC, Jaiswal RK, Douglas R, Mosca JD et al. Multilineage potential of adult human mesenchymal stem cells. Science 1999; 284(5411): 143-147.

28 Mackenzie TC, Flake AW. Human mesenchymal stem cells persist, demonstrate site-specific multipotential differentiation, and are present in sites of wound healing and tissue regeneration after transplantation into fetal sheep. Blood Cells Mol Dis 2001; 27(3): 601-604.

29 Ishizaki M, Wakamatsu K, Matsunami T, Yamanaka N, Saiga T, Shimizu Y et al. Dynamics of the expression of cytoskeleton components and adherens molecules by fibroblastic cells in alkali-burned and lacerated corneas. Exp Eye Res 1994; 59(5): 537-549.

30 You L, Kruse FE. Differential effect of activin A and BMP-7 on myofibroblast differentiation and the role of the Smad signaling pathway. Invest Ophthalmol Vis Sci 2002; 43(1): $72-81$.

31 Nakamura K, Kurosaka D, Yoshino M, Oshima T, Kurosaka $\mathrm{H}$. Injured corneal epithelial cells promote myodifferentiation of corneal fibroblasts. Invest Ophthalmol Vis Sci 2002; 43(8): 2603-2608. 
32 Pellegrini G, Dellambra E, Golisano O, Martinelli E, Fantozzi I, Bondanza S et al. p63 identifies keratinocyte stem cells. Proc Natl Acad Sci USA 2001; 98(6): 3156-3161.
33 Parsa R, Yang A, McKeon F, Green H. Association of p63 with proliferative potential in normal and neoplastic human keratinocytes. J Invest Dermatol 1999; 113(6): 1099-1105. 